\title{
Protecting Children from Violent TV Programmes and Video Games in Tanzania
}

\author{
${ }^{1}$ Mwinyimbegu, K.S \\ Taro Nora Consulting, P.O. Box 85 \\ Kaliua, Tanzania
}

\begin{abstract}
Violent Television programmes and video games have been consistently found to have negative impact on children's education and behaviour. Past and current research on the attitudes of children watching violent television and video games show that children who watch violence in television and video games imitate the violent behaviours of the actors they watch in the television and video games. In Tanzania the influence of violent movies and video games on the education of children is an issue of great concern to parents, pediatricians, educators, researchers, and policymakers. However, very few studies have been undertaken to assess the debilitating effects of violent television programmes and video games on children's education and attitudinal behaviour. This paper presents the findings of a study undertaken to assess the effects of violence in television and video games on children's education and attitudinal behaviour. The study's setting was Isenge Primary School, Pasiansi Ward, in the city of Mwanza. A total of 1,183 pupils were involved where 133 were randomly interviewed. The attitudes of the pupils were assessed by the Child and Adolescent Social Perception Measure (CASP). Results showed that the pupils' attitudinal behaviours were substantially influenced by violent Television programmes and video games.
\end{abstract}

Keywords:- Violent Television Programmes, Video Games, Influence, Child Education, Protection

\section{INTRODUCTION}

Television and video games have strong influence on the attitudes and behaviours of the viewers particularly children (UNICEF 2000). Research on the impact of media on society shows that in today's society the electronic media has become increasingly integrated into the lives of children in particular the action television movies, video and computer games (Schwartz and Proctor, 2000). Current global trends illustrate that children are particularly affected, either physically, cognitively, psychologically and socially by such violent manifestations in the electronic media (Fox, \& Leavitt, 2000). The impact of the electronic media on children's behaviour has been found to be exacerbated by risk factors that increase the incidence of violence such as parental socio-economic status (SES), unemployment, alcoholism, divorce and domestic violence (McIntosh, 2002).

\author{
${ }^{2}$ Kubyula, N \\ PhD Candidate \\ The Open University of Tanzania \\ Department of Social Work
}

Three major categories of studies have so far been undertaken and they range from laboratory experiments to long-term fieldwork and ethnographic studies with children at school and home (Singer \& Singer, 1981). The first category is that of laboratory research in which a cohort group of children is selected and exposed repeatedly to movies and video games that contain violent scenes. Then the children are asked to play the roles of the main actors in the movies and video games and how they would act in real situation. The objective of such experiments is to observe the immediate changes that occur in the children's attitudes and behaviour.

The second category of studies has involved observational fieldwork studies in which aggressive behavior and exposure to media violence are assessed in samples of children in their home and school environments. These studies have demonstrated that children who behave more aggressively on the average watch and prefer to watch more violent TV shows and movies (Eron, 1963). The third category of studies has been that of longitudinal field studies in which children's exposure to media violence and their actual aggressive behavior are assessed at two or more points in their lives.

The attitudinal and behavioural impact of violence in the television and video games has been more evident in developed countries particularly in Europe and North America (Krcmar and Vieira, 2005). Longitudinal studies in the US show that children aged between 6 and 14 spend a lot of time watching violent TV programmes and playing video games for an average time of 13 hours per week for boys, on average, and 5 hours per week for girls (Gentile et al 2004). There are numerous cases in the USA about school children shooting their classmates, friends, teachers and even parents (Kracke and Hahn 2008). Killing another human being is action that children in the developed countries take it as something normal. The children who have committed these murders said that they learned it from violent television and video games.

A study conducted by UNESCO (1998) showed that 93\% of the children in the world have access to a TV-set and that in the North-Western hemisphere the rage was 99\% and $83 \%$ for Africa with Asia and Latin-America in between. It was found out that at least $50 \%$ more time spent with this medium than with any other out-of-school activity including home-work, being with family or friends, or reading. The central thesis is that in most of these studies has been that TV and video games have negative influence 
in children. Enron (1963), Botha (1990), Comstock (1991), and Comstock and Park (1991) contend that too much exposure to television and video games is harmful to the children educational performance.

\section{Theories of media violence}

Theories of media violence postulate that the violence in the media has a negative impact on the viewers (Christakis et al 2004). Potter and Warren (2006) as well as Rockler-Gladen (2008) contend that there is debate among media researchers and lawmakers what should be done to protect children from the harmful effects of violence on television. However, some researchers contend that the effects of media violence are mitigated by other factors and that they are rarely direct but indirect. Researchers like Robinson et al (2001) believe that there is a strong correlation between children's excessive exposure to media violence and real-life behavior. But other theorists argue that the issue of media violence researchers has been grossly overstate. They argue that the violence in the television and video games does not impact individuals or society as much as many believe (Walsh \& Gentile, 2001).

\section{THEORIES OF MEDIA VIOLENCE}

\section{$>$ The magic bullet theory}

The idea behind this theory is that messages in TV and video games impact people in direct, measurable, and immediate ways the same way like the bullet does when it enters the body (Rockler-Gladen 2008). The TV and video games aree considered to be like a magic bullet in terms of their influence on children's moral reasoning and behaviour. The influence of TV and video games is thought to be very fast and lasting. For example, when someone watches a commercial on a certain product such as Coca Cola and then he/she is likely to order it or like to drink it immediately. Similarly, music and music videos are pushing into new and increasingly violent behaviour among children.

\section{$>$ Cultivation theory}

Cultivation theory posits that TV and video games cultivates a common culture among children. This is due to the fact that TV and video games are like the public's storyteller and main source of influencing the audience (Paik and Comstock, 1994). Repeated viewing the TV and video games makes children used to the stories that are told. They eventually believe the stories as something that presents broad, underlying, global assumptions about the "facts" of life rather than the specific attitudes and opinions. The argument is that TV and video games cultivate a "dominant" or mainstream set of cultural beliefs, values and social practices (Eron \& Huesmann, 1986). In this way TV and video games cultivates common perspectives among viewers as it fosters similar views and perspectives among those who, on the surface, should be very different (Honig, 1983)

\section{$>$ Desensitization theory}

This theory posits that by watching TV and video games more frequently the children become "desensitized", that is, get used to watching violence. The children get used to watching violence in the Television so much that violence no longer makes a strong emotional impact upon them (Gentile, Lynch, Linder, \& Walsh 2004). Research has shown that by watching lots of violent movies, a child no longer gets upset while watching violent movies in TV and video games (Anderson, \& Bushman, 2001).

In Africa the impact of violence in the television and video games has been identified as one of the factors that has resulted into unruly and aggressive behaviour among children both at home and in schools (Kremar and Vieira, 2005). Studies in South Africa have shown that violence in television and video games have been contributing to an increase in children's aggressive behavior at schools and colleges, increase in children and adolescent mental health illnesses, petty crimes, prostitution, alcohol and drug addiction (Raviv et al 1999). Studies in Ghana (OseiHwere, 2006) and Nigeria (Gbadeyan, 2010) have shown that children exposed to violence in television and video games have been imitating violent and criminal acts. Such behaviours have become chronic social problems so much that teachers at school are having difficulties in disciplining the children while parents in homes were having problem in handling their children (George and Larry 1996).

In Tanzania the impact of violence in television and video games has become an issue of great concern to pediatricians, educators, researchers, and policymakers (URT, 2009). Today there are over $20 \mathrm{TV}$ stations and thousands of video games that are easily accessible to almost all the children in the country. Those concerned argue that despite the fact the electronic media was introduced in the early 1990s mainly in urban areas, yet the influx of violent movies and video games which have spread all over the country even in remote rural areas has had negative impact on children (HakiElimu 2014). With the freedom of the media being the country's policy there is no censorship or control on what TV stations and video games should contain. The TV stations are free to show any program they like with no restrictions from the government. Most of the programmes shown by almost all TV stations and video games range from entertaining and educative to violent movies that are damaging to the children.

Reports from Social Welfare Department (MoHSW, 2011) in the regions indicate that the past 10 years there has been an increase in the occurrence of child aggressiveness and abuse. In recent years parents, the clergy, child specialists, NGOs and social workers have been raising concern that violence in TV and video games is having negative impact on the psychological well being and behaviour of the children in Tanzania (Daily News, 15 October 2011). 
In response to this and other impacts on children educational development, the government of Tanzania passed in 2002 the Child Act which among other things restricted children's exposure to violence both in and outside the home (URT, 2002). The Act sought to protect children from all sources of violence and abuse. But with no censure of what type of movies should be cast by television stations, children continue to be exposed to violent movies and scenes. The availability of video games in the market implies that children continue to be the target of the electronic media.

But despite taking such measures yet the exposure to violence in TV has continued especially in urban areas where children can view violent movies cast by the television stations during prime hours and also in halls that show videos which contain violent acts. The videos are also sold in public places with no controls and restrictions. Young children can such videos without being questioned or she/he can watch them in entertainment halls where children are allowed to attend without any restrictions.

\section{$>$ Problem statement and delimitations}

Children in Tanzania are too much exposed to violence in the television and video games. The impact of this woeful culture is being experienced by the way children imitate the violent behaviours from the television and video games that they are exposed without restrictions. There are complaints over abnormal children behaviours from teachers, parents, religious leaders, pediatricians, educators, researchers, policymakers and social workers. Some parents and teachers argue that TV and video games literally ruins children's educational potential, creativity, imagination and school achievement. However, such claims are vehemently disputed by parents who argue that it is not true that violence and criminal acts in TV and video games influence children to become aggressive, criminals and bullies at school. They contended that television and video games have nothing but positive effects on children. They argue that actually the television and video games keep the children "off the streets". Research on this issue has not yet been carried to substantiate the nature of the influence TV and video games children's attitudinal behaviour. It is in view of this gap that this study was undertaken.

\section{$>$ Objective}

The objective of this study was to assess the impact of violent TV programmes and video games on the education and attitudes of the children in primary schools.

\section{METHODS}

\section{$>$ Research Design}

The study was cross-sectional using semi-structured interviews with the children, parents and teachers. A formal letter of introduction with the details of the research proposal was submitted to the city council of Mwanza in order to allow me to carry out the study. Discussions were held with city officials in the departments of education and community development and social welfare about primary schools where the study should be carried out. The authorities included the ward councilors and head teachers from Pasiansi ward in Ilemela district. It was agreed that Isenge Primary School will be an ideal setting for the study due to its nearness to the city centre.

After having secured the go-ahead from the city and school authorities' letters of introduction and consent forms were sent to the head teacher and parents of the children were selected to attend a meeting at the school to be informed about the study and their roles as participants. The parents attended in larger number and objectives and significance of the study were explained to how they will participate. About 100 parents from those who had television sets and video games as well as those who did not own televisions and video games volunteered agreed to participate in the study. The parents were assured that their identity and information they will provide will not be revealed.

After that I collaborated with the head teacher and teachers of classes that were involved to select randomly the pupils who would participate in the study. The pupils were selected according to age, gender and whether or not at home there was television or video game sets.

\section{Setting \\ - Isenge Primary School}

This study was carried out at public primary school that is known as Isenge primary school. This primary school is found in Pasiansi ward in Mwanza city which is located on the southern shores of Lake Victoria in Northwest Tanzania. The primary school was established in 1963 to serve pupils from the surrounding areas both as a nursery and primary school. It started as a small primary school that was built to be a nursery and primary school but has been growing over the years to become very famous. Up to the time this study was being carried out the school had a total of 1,183 pupils, out of which 596 are girls and are 587 boys. The total number is particularly large that outstrips the school's intake capacity. According to the head teacher the school's intake capacity is overwhelmed in the sense that they are so many children.

Isenge primary school is among a total of 155 primary schools out of which 139 primary schools are government owned and 16 are private owned. There are 1,552 primary teachers of whom 1,310 are teaching government primary schools and 242 are teaching private primary schools (Mwanza City Council, 2011). There are 94,530 pupils of whom 90,355 are studying at government primary schools and 4,175 are studying at private primary schools. Mwanza City has got 203 nursery schools of which 79 are registered and 124 are not yet registered. Private institutions own 40 nursery schools and the government owns 39 nurseries.

\section{$>$ Study population}

The population for this study was 1,183 pupils, out of which 596 are girls and 587 were boys. The pupils come from neighboring areas and some come as far as areas like Kirumba, Ilemela and Nyamagana. Most of the children in this area like schooling and according to the head teacher 
the rate of drop out is relatively low compared to other areas. The parents of these children include civil servants, small and medium business people, peasants and those who are self employed in micro and small businesses. Most of the parents have television sets at home while a relatively average number have video game sets as well.

General demographic information was collected for all participants. The age of pupils ranged from 9 to 18 years with a mean age of 8 years. All participants were from areas around the school with almost all the parents being either employed or unemployed. The majority of parents had an average of four children.

\section{Sample size}

This cross-sectional study involved 133 pupils from two primary schools and 100 parents from Pasiansi in Ilemela district, Mwanza city. The pupils and parents were sampled in two different ways namely, the study group and control group. Random sampling was used to get a sample of 200 pupils and parents for this study. Out of this sample 50 pupils and 50 parents were recruited as a study group whose homes have television sets and video games while 50 pupils and 50 parents were recruited as a control group whose homes did not have television sets and video games. The pupils were recruited from standards three, four, five, six and seven as shown in Table 1 below.

\begin{tabular}{|c|c|c|c|c|c|c|}
\hline Standards/Classes & Boys & \% & Girls & \% & Total & \% \\
\hline Three & 17 & 55 & 14 & 45 & 31 & 23 \\
\hline Four & 18 & 45 & 22 & 55 & 40 & 30 \\
\hline Five & 12 & 48 & 13 & 52 & 25 & 19 \\
\hline Six & 8 & 50 & 8 & 50 & 16 & 12 \\
\hline Seven & 11 & 52 & 10 & 48 & 21 & 16 \\
\hline Total & $\mathbf{6 6}$ & & $\mathbf{6 7}$ & & $\mathbf{1 3 3}$ & $\mathbf{1 0 0}$ \\
\hline
\end{tabular}

Table 1:- Pupils selected for the study Source: Fieldwork notes

\section{> Data Collection Methods}

- Child and Adolescent Social Perception (CASP)

This instrument was used to collect the views of the children about violence in the television and video games (Magill-Evans, Koning, Carneron-Sadava, \& Manyk 1995). The CASP instrument consisted of children viewing 10 unrelated violent video games for three minutes. Collection of the views of the children included providing contextual information and presenting multiple cues simultaneously. The scenes in the video games were auto-filtered so that the meaning must be derived from nonverbal and situational cues. The children participating in the study were required to provide answers to questions about how the people in the scenes were behaving in terms of identifying the different cues such as facial expressions and gestures. The aim of using this instrument was to determine the manner that would stimulate the type of social interactions the children would interpret in real life after viewing the video games.

\section{- Emotion Score (ES)}

The children's answers were written down and later compared to an answer key which was then used to assign points depending on how accurate the children got the answer. Completion of this exercise was expected to provide two scores. First, the focus was on the total emotion score (ES) which referred to a child's to generate answers questions about how the people in the video games acted.

\section{- Nonverbal cue score (NCS)}

The second focus was on the total nonverbal cue score (NCS) which was meant to reflect the child to identify the different cues in terms of facial expressions and gestures. The overall objective was to assess school adjustment and social competence. To achieve the objective of collecting data in a systematic way the relationship between social perception and what the children viewed in the video games I constructed the matrix shown in Table 2 below. In this matrix it was hypothesized that there would be high $(\mathrm{H})$, moderate (M) and low (L) correlations. 
ISSN No:-2456-2165

\begin{tabular}{|c|c|c|c|c|c|c|}
\hline Variables & $\begin{array}{c}\text { CASP } \\
\text { ES }\end{array}$ & $\begin{array}{c}\text { CASP } \\
\text { NCS }\end{array}$ & T-PB & P-PB & S-AB & AC \\
\hline $\begin{array}{c}\text { CASP ES } \\
\text { (Emotion Scores) }\end{array}$ & - & - & - & - & - & - \\
\hline $\begin{array}{c}\text { CASP NCS } \\
\text { (Nonverbal Cue Score) }\end{array}$ & $\mathrm{H}$ & $\mathrm{M}$ & $\mathrm{M}$ & $\mathrm{M}$ & $\mathrm{M}$ & $\mathrm{L}$ \\
\hline $\begin{array}{c}\text { T-PB } \\
\text { (Teacher-P referred Social Behaviour) }\end{array}$ & $\mathrm{M}$ & $\mathrm{M}$ & $\mathrm{L}$ & $\mathrm{L}$ & $\mathrm{L}$ & $\mathrm{L}$ \\
\hline $\begin{array}{c}\text { P-PB } \\
(\text { Peer-Preferred Social Behaviour) }\end{array}$ & $\mathrm{M}$ & $\mathrm{M}$ & $\mathrm{M}$ & $\mathrm{L}$ & $\mathrm{L}$ & $\mathrm{L}$ \\
\hline $\begin{array}{c}\text { S-AB } \\
\text { (School Adjusted Behaviour) }\end{array}$ & $\mathrm{M}$ & $\mathrm{M}$ & $\mathrm{H}$ & $\mathrm{H}$ & $\mathrm{M}$ & $\mathrm{L}$ \\
\hline $\begin{array}{c}\text { AC } \\
\text { (Academic Competence }\end{array}$ & $\mathrm{M}$ & $\mathrm{M}$ & $\mathrm{M}$ & $\mathrm{M}$ & $\mathrm{H}$ & $\mathrm{L}$ \\
\hline
\end{tabular}

Table 2:- Hypothesized Correlation Matrix of Variables Related to CASP

Source: Adapted from Guttner, V.D (2000) Validation of the Child and Adolescent Social Perception Measure, Master of Education thesis, University of Alberta, Canada

\section{Retrospective Interview}

Retrospective interview was used whereby the pupils were asked to look backward and recall violent TV movies and video games which they watched a few months ago or in the years that have passed (Harrison and Cantor 1999). The efficacy of retrospective interview was also confirmed in a study carried out by Brewin, Andrews and Gotlib (1993) who found that when adults are asked to recall salient factual details of their own childhoods are generally more or less accurate especially in terms of events that have been unique, consequential, frightening, influential, traumatic or fulfilling. Thus, in this study the pupils were asked to remember specific TV programmes and video games and explain how those programmes influenced their lives.

\section{Focused Group Discussion}

Focused group discussion (FGD) was used to assess the pupils their views about violence in televisions and video games. The discussions devoted much of the time on the extent to which the pupils believed that the actions they saw in the television and video games were actual or fiction. Also the discussion focused on the extent to which most of the children copied the actions and behaviours of the people in the video games.

\section{DATA ANALYSIS AND RESULTS}

\section{A. Data Analysis}

The data was analyzed by using Statistical Package for the Social Sciences (SPSS). A MANOVA was used to analyze whether or not there was a significant difference based on gender for sub-test scores. In order to be precise used a $t$-test to analyze the differences in the means of boys and girls in their perceptions of the effects of exposure to violence in television violence and video games on their behavior. The t-test was used to assess whether the means of two groups will be statistically different from each other.

B. Results

$>$ Mean and Standard Deviations for Subtest Scores

It was hypothesized that if there was a gender effect on television and video games then the remainder of the statistical analysis would be computed for boys and girls separately. We found out that there were no significant differences and therefore pooled the data for further analysis. Then we computed and compared the data to the hypothesized matrix in Table 2 above. The Mean and Standard Deviations for Subtest Scores are shown below in Table 3.

\begin{tabular}{|c|c|c|c|}
\hline \multicolumn{3}{|c|}{ MEAN (SD) } & Females \\
Variables & $\begin{array}{c}\text { Males } \\
\text { N=72 }\end{array}$ & $\begin{array}{c}\text { Total } \\
\text { N=133 }\end{array}$ & $35.05(8.22)$ \\
\hline Emotion Scores & $33.13(8.37)$ & $36.28(7.95)$ & $44.74(10.51)$ \\
\hline Nonverbal Cue Score & $43.44(9.96)$ & $45.57(10.84)$ & $60.91(14.98$ \\
\hline Teacher-Preferred Behavior & $56.56(13.89)$ & $63.66(15.11)$ & $66.99(15.18)$ \\
\hline Peer-Preferred Behavior & $63.00(14.44)$ & $69.54(15.21)$ & $38.94(10.32)$ \\
\hline School Adjustment Behavior & $35.49(10.44)$ & $41.15(9.69)$ & $32.25(9.50)$ \\
\hline Academic Competence & $30.13(9.85$ & $33.61(9.09)$ & \\
\hline
\end{tabular}

Table 3:- Mean and Standard Deviations for Subtest Scores

Source: Analysis of participants' demographics, April-June 2012 


\section{Pupils' CASP scores}

Table 4 describes the pupils CASP scores in terms of how they imitate the violence in TV and video games. Pearson correlations were used to examine the relationship among test scores and to compare to the hypothesized matrix. This means that most pupils see themselves in the actions and behaviours of the actors in the movies and video games. This is similar to the study of Magil-Evans et al (1995) who recorded similar CASP scores for children aged 10 and 11 in a normative sample (n=44).

\begin{tabular}{|c|c|c|c|c|}
\hline CASP & Lower range & Upper range & M(SD) & Total Score \\
\hline Emotion Score & 13 & 54 & $35.05(8.22)$ & 86 \\
\hline Nonverbal Cues Score & 23 & 77 & $44.74(10.51)$ & 135 \\
\hline
\end{tabular}

Table 4:- Pupils CASP Scores for Total Sample ( $\mathrm{N}=100)$

Source: Interviews and discussion with pupils

The results showed there is correlation between CASP and Emotion Scores as well as Nonverbal Cue Score were as high. This means that the children showed more inclination to watching movies that contained violence, pornography and music than educative programmes.

\section{Time Spent Watching TV or Video Games}

Table 5 shows that our children spend more time watching and television and video games. Our study shows that $90 \%$ of the pupils agreed that many children in the study area spend most of their time watching movies and video games. This happens when they come back from school and during the holidays and weekends. The study also found that there is a compulsive fascination with the supernatural and violence programmes. Children in our homes have no restrictions on watching TV and video games since they are free to watch TV and video games with their friends and less with parents. About 55\% watch movies and video games at pubs and halls. Also most of the children watch TV and video games almost every day (85\%) and when they come from school. This means they use their time to do homework to watch TV and video games.

\begin{tabular}{|c|c|c|}
\hline & Amount of TV viewing and video games & Agree \\
\hline 1. & Many children spend time watching TV and video games & $75 \%$ \\
\hline 2. & Everyday & $85 \%$ \\
\hline 3. & Weekends and holidays only & $35 \%$ \\
\hline 4. & When comes from school & $65 \%$ \\
\hline 5. & Alone in the room & $25 \%$ \\
\hline 6. & Together with brother/sister/friends & $90 \%$ \\
\hline 7. & Together with parents & $45 \%$ \\
\hline 8 & At friends' homes & $95 \%$ \\
\hline 9. & At pubs and halls & $55 \%$ \\
\hline
\end{tabular}

Table 5:- Participants views children spending more time watching TV and video games Source: Interviews and discussion with pupils

\section{$>$ Preferred movies and video games}

Most the pupils said it is usually "cute" and "entertaining" to watch such actions taking place in the TV and video games. They said they liked violent and aggressive movies because such movies encouraged them to be "strong" and able to defend themselves when bullied by other children at school or in the streets. Some of the pupils said they liked watching love movies because love movies were much more entertaining than violent movies. Other pupils said the liked watching sports programme especially major European football leagues like the Premiere League, La Liga and Italian Serie A League.

\begin{tabular}{|c|c|c|c|}
\hline & Movie or video game & Preference & Score \\
\hline 1. & War games & Most preferred by boys & $75 \%$ \\
\hline 2. & Murders & Most preferred by boys and girls & $65 \%$ \\
\hline 3. & Revenge & Most preferred by boys & $85 \%$ \\
\hline 4. & Nakedness & Most preferred by boys & $90 \%$ \\
\hline 5. & Pornography & Most preferred by girls & $90 \%$ \\
\hline 6. & Love story & Most preferred by boys and girls & $95 \%$ \\
\hline 7. & Music & &
\end{tabular}

Table 6:- Preferred films and video games by pupils Source: Interviews and discussion with 


\section{CONCLUSION}

This study has provided just tip of the iceberg about the impact of violent TV programmes and video games on children's educational and attitudinal behavior. The study has generally stated the case for further studies on how the violent TV programmes and video games influence the children's mental and physiological state of agressionhave negative influence on the education of the children. The findings of this study have shown that children in the area where the research was carried out have been strongly influenced to watch action television movies and video games. What this study has done is to pioneer in this complex but important area of child psychology and wellbeing. Television and video games have become the most common tools for children to relax other than playing games outside home or doing their home works. As the research has shown the children in the area prefer movies which contain violent and immoral actions. These findings are similar to what was found in studies carried out in the USA, Canada Europe, and India where many children were found to like more the movies and video games that portray violence scenes like war games, mass killings and immoral acts like nudity and pornography.

This study has set out the pace for more studies to be carried in urban and rural areas in Tanzania to determine the extent of the psychological effects of violence in television and video games on children's attitudinal behaviours. This is due to the fact there is today great concern among parents and social workers about the negative impact on children caused by immoral movies that are shown in the television and video games. In view of this situation we recommend the following steps to be taken:

\section{$>$ Short and Longitudinal studies should be carried out}

Short and longitudinal studies should be undertaken in many parts of the country in order to come up with comprehensive information on the psychological and physiological effects of the violence in TV and video games on the children's cognitive, moral behaviors and schooling. Such studies should be carried out in rural and urban areas in order to determine the extent to which the problem has spread out across the country. The findings will certainly inform policy makers, child care institutions and parents to take appropriate steps to arrest the situation.

\section{Strict censure and control of action TV programmes,} movies and video games

The government should censure and control the importation or production of violent movies and video games. We recommend that movies and video games that portray violent and immoral acts should not be allowed in the country. Instead, child-friendly movies and video games should be allowed in the country. TV programmes that portray violent and immoral scenes should be banned. Instead, TV stations should be encouraged to prepare children programs that portray good and responsible moral behavior for children as future parents, leaders and citizens of this country.
- Parental control on time children spend watching television and video games

Parents should be reminded of their responsibilities to make sure that their children do not spend too much time watching television and video games. Some parents have the tendency of allowing children to have access to television and video games. Parents should be education about the psychological and physiological effects of too much television and video games on the well being of their children. Parents should make sure that children watch TV and play video games at specific times of the day or week. Children should not be allowed to watch TV and video games alone or with their friends.

\section{$>$ Provide counseling to affected children and parents}

Guidance and counseling should be provided to children and parents who are affected by the violence in TV and video games. This service is extremely important because there is information that there are today many children who have been "addicted' by TV and video games so much that they are uncontrollable. Many children are said to have absolute freedom to watch whatever they like and parents seem to have given up or failed completely to restrict or control their children. Social workers will have to be sent into such homes to deal with those problems. But the general society should also be sensitized to address this problem.

\section{REFERENCES}

[1]. Anderson, C. A., \& Bushman, B. J. (2001). Effects of violent games on aggressive behavior, aggressive cognition, aggressive affect, physiological arousal, and pro-social behavior: A meta-analytic review of the scientific literature. Psychological Science, Vol. 12, pp. 353-359. Accessed at: http://www.apa.org/research/action/games.aspx

[2]. Anderson, C. A., Berkowitz, L., Donnerstein, E., Huesmann, L. R., Johnson, J., Linz, D., Malamuth, N., \& Wartella, E. (2003). The influence of media violence on youth. Psychological Science in the Public Interest, Vol. 4, pp. 81-110. Accessed at: http://www.apa.org/research/action/games.aspx

[3]. Botha, M. (1990). Television exposure and aggression among adolescents: A follow-up study over 5 years, Aggressive Behavior.

[4]. Bushman, B. J., \& Geen, R. (1990). Role of cognitiveemotional mediators and individual differences in the effects of media violence on aggression. Journal of Personality and Social Psychology, 58, 156-163.

[5]. Comstock, G. A. (1980). New emphases in research on the effects of television and film violence. In: E. L. Paler \& A. Dorr (Eds.), Children and the faces of television: Teaching, violence, selling. New York: Academic Press.

[6]. Comstock, G. A., \& Paik, H. (1991). The effects of television violence on aggressive behavior: A metaanalysis. In: A preliminary report to the National Research Council on the understanding and control of violent behavior. Washington, DC: National Research Council. 
[7]. Eron, L. D. (1963). Relationship of TV viewing habits and aggressive behavior in children. Journal of Abnormal and Social Psychology, 67, 193-196.

[8]. Eron, L. D., \& Huesmann, L. R. (1986). The role of television in the development of pro-social and antisocial behavior. In: D. Olweus, J. Block \& $\mathrm{M}$. Radke-Yarrow (Eds.), Development of anti-social and pro-social behavior, (pp. 285-314). New York: Academic Press.

[9]. Gentile, D. A. \& Anderson, C. A. (2003). Violent video games: The newest media violence hazard. In D. A. Gentile (Ed.), Media violence and children. Westport, CT: Praeger Publishing. Accessed at: http://www.apa.org/research/action/games.aspx

[10]. Gentile, D. A., Lynch, P. J., Linder, J. R., \& Walsh, D. A. (2004). The effects of violent video game habits on adolescent aggressive attitudes and behaviors. Journal of Adolescence, Vol. 27, pp. 5-22. Visit: http://www.apa.org/research/action/games.aspx

[11]. Gbadeyan, R. A. (2010). Content analysis of selected television commercials to children in Lagos State Nigeria. African Journal of Marketing Management Vol. 2(5) pp. 101-106, August 2010. http://www.academicjournals.org/ajmm

[12]. Huesmann, L. R., Eron, L. D., Klein, R., Brice, P., \& Fischer, P. (1983). Mitigating the imitation of aggressive behaviors by children's attitudes about media violence. Journal of Personality and Social Psychology, 44, 899-910.

[13]. Johnson, A. (1986). TV: A threat or a complement to school? Journal of Educational Television, 12, 29-38.

[14]. Kaiser Family Foundation (2004). The role of media in childhood obesity (No. 7030). Menlo Park CA: The Henry J. Kaiser Family Foundation.

[15]. Kracke, K., and Hahn, H. 2008. The nature and extent of childhood exposure to violence: What we know, why we don't know more, and why it matters. Journal of Emo-tional Abuse 8(1/2):29-49.

[16]. Krcmar, M. and Edward T. Vieira, Jr (2005). "Imitating Life, Imitating Television: The Effects of Family and Television Models on Children's Moral Reasoning". Communication Research, Vol. 32 No. 3, June 2005 267-294. Available at: http://crx.sagepub.com/cgi/content/abstract/32/3/267

[17]. Maxfield, M.G., \& Babbie, E. (2001). Research methods for criminal justice and criminology. Belmont, CA: Wadsworth.

[18]. Osei-Hwere, E. M. (20080, Mass Communication Children's Television in Ghana: History, Policy, Diversity, and Prospects in a Changing Media Environment. $\mathrm{PhD}$ dissertation available at: http://etd.ohiolink.edu/sendpdf.cgi/OseiHwere\%20Enyonam\%20M.pdf?ohiou121 $\underline{8685896}$

[19]. Parke, R. D., Berkowitz, L., Leyens, S. P., West, S., \& Sebastian, R. S. (1977). Some effects of violent and nonviolent movies on the behavior of juvenile delinquents. In: L. Berkowitz (Ed.), Advances in experimental social psychology (Vol. 10, pp. 135172). New York: Academic Press.
[20]. Robinson, T. N., Wilde, M. L., Navracruz, L. C., Haydel, K. F., \& Varady, A. (2001). Effects of reducing children's television and video game use on aggressive behavior: A randomized controlled trial. Archives of Pediatric Adolescent Medicine, Vol. 155:17-23

[21]. Singer, J. L., \& Singer, D. G. (1981). Television, imagination, and aggression: A study of preschooler's play. Hillsdale, NJ: Lawrence Erlbaum.

[22]. Slotsve, del Carmen, Sarver, and Watkins (2008). Television Violence and Aggression: A Retrospective Study. Southwest Journal of Criminal Justice, Vol. 5(1), pp. 22-49.

[23]. Walsh, D. A. \& Gentile, D. A. (2001). A validity test of movies, television, and videogame ratings. Pediatrics, Vol. 107:1302-08. http://www.apa.org/research/action/games.aspx

[24]. UNESCO (1998). The UNESCO Global Study on Media Violence: A Joint Project of UNESCO, World Organization of the Scout Movement and Utrecht University. UNESCO, Paris, 19 February 1998.

[25]. United Republic of Tanzania (2009). Act of the Child 2009. Dar es Salaam. 